\title{
Innovative improvement method for e- learning quality: A case of government organizations
}

\author{
Shu-Ping Lin ${ }^{1}$ Thao-Minh $\mathbf{H o}^{2}$ Chia-yen Hsieh ${ }^{1^{*}}$ \\ ${ }^{1}$ Department of Technology Management, Chung Hua University, 707, Sec.2, WuFu Rd, \\ Hsinchu 300, Taiwan ROC, splin@,chu.edu.tw \\ ${ }^{2} \mathrm{Ph} . \mathrm{D}$ Program of Technology Management, Chung Hua University, \\ sissi_hai@yahoo.com
}

\begin{abstract}
This study aims to establish an innovative method for effectively identifying the extreme key factors toward e-learning satisfaction and learning effect in the case of government organizations. The findings hope to provide future research and relevant managers with a helpful improvement method and guidelines for enhancing e-learning quality in order to achieve better development and competitiveness.
\end{abstract}

Keywords: e-learning, improvement solutions, QFD

\section{Introduction}

With rapidly developing information technologies, e-learning has gained dramatically increasing demands from schools, businesses, institutes, and government organizations [1]. Many countries have attempted to enhance elearning to stimulate international competitiveness through promoting an effective knowledge economy, organizational learning, and employee self-improving professional knowledge and skill development [2]. Hence, e-learning management has become one of the topconcerned issues globally.

Bearing beneficial features, e-learning has been widely perceived as the revolu- tionary education which effectively allows and self-paced learning, better information accessibility, content delivery, interactivity, on-demand availability, learning convenience, and time and space flexibility, and enhances knowledge reuse and sharing [3], [4]. Due to these benefits, e-learning quality enhancement is believed to positively impact users' learning effects and satisfaction [5]. However, despite the increasing growth rate worldwide, it is noted that e-learning failures still exist and little is known about why users stop their using e-learning after early-stage experience [1]. Hence, how to improve e-learning quality has become a critical issue and challenge globally.

Previous studies have attempted to point out possible influential factors toward e-learning success [2]; however, missing from literature is the investigation on key failure factors and the most appropriate recovery solutions. Taking this point, this paper aims to develop an innovative methodology which can bridge these gaps through (1) identifying the key e-learning quality failure factors which significantly influence users' overall satisfaction and (2) seek feasible improvement solutions. As such, this study initially explores the determinant failure factors and their recovery capability ranking; then the Quality Function Deployment (QFD) method is utilized to find out 
the most capable recovery solutions. By doing this, this paper provides future research with useful references method for e-learning quality improvement.

It is noted that flexible e-learning plays a critical role to government organizations' competitiveness since it helps satisfy continuing professional training demands, promotes employees' selfimproving learning, and facilitates training for costly specialized tasks [6]. Hence, this study aims to take the case of government organizations for investigation. As such, this study offers helpful guidelines for promoting e-learning quality for the sake of relevant users, businesses, and especially government organizations. Unlike previous studies focusing on all possible e-learning quality gaps, the greatest contribution of this study is to identify the critical e-learning failure factors and the most feasible recovery strategies, which in turn makes the e-learning quality improvement implementation more effective.

\section{Literature review}

E-learning is defined as the innovative web-based system approach to education and training which utilizes telecommunication technology to deliver information, learning content, and instructions; hence, information is made available regardless of time and space restrictions [1], [4].

In extant literature, several common dimensions (i.e. students, instructors, courses, technologies, system design, and environment) have been utilized to assess a wide range of influential factors to users' satisfaction on e-learning [1], [4]. Due to the research purposes, this study utilizes the above suggested dimensions and factors as a basis for the establishment and modification of the survey items. Consequently, a total of 38 final influential factors are identified under two perspective angles of e-learning providers (31 factors) and learners (final 7 factors), namely (1) state-of-the-art equipment, (2) sufficient hardware, (3) sufficient software, (4) sufficient digital network bandwidth, (5) perceived ease of use, (6) account security/privacy, (7) instructions' professionalism and assistance capability, (8) course topics, (9) easy teaching content, (10) correct content, (11) useful content, (12) content diversity, (13) inspiring content, (14) auxiliary teaching resources, (15) alternative teaching resources, (16) learning assessment mechanism, (17) e-learning support system (i.e. curriculum update, instant consultation, feedback), (18) institutions' support in providing e-leaning guidelines, (19) available professional staff for guidance and assistance, (20) course curriculum, (21) managers' support for e-learning use, (22) e-learning inspiring environment, (23) proposed course benefits, (24) new technology adoption in e-learning system, (25) reward systems, (26) awarded recognition, (27) certificate achievement, (28) learning outcomes as a basis for job promotion, (29) sense of honor enhancement for participation, (30) punishment mechanism, (31) perceived relationship between e-learning use and job performance enhancement, (32) learners' operating skills, (33) learners' professional background, (34) learning motivation of obtaining new knowledge, (35) learning motivation from peer pressure, (36) learning motivation from work demand, (37) interactions, and (38) learners' sense of being excluded from e-learning courses.

\section{Methodology}

The research samples were from 5 various government Ministries of Transportation, Finance, Interior, Economy, and Education. It is noted that the total number of staff of these Ministries are approximately adequate, ranging from 115 to 127 people. Out of 750 distributed survey questionnaires, 599 valid question- 
naires were returned with a response rate of $79.8 \%$. The Likert 5-point scale was used to assess the above 38 factors for degrees of importance and the overall satisfaction $(1=$ "significantly unimportant" or "totally dissatisfy", 5= "significantly important" or "totally satisfy").

Based on the research goals, this study proposes the innovative 2-stage methodology SFI-QFD to identify the extreme key factors as a basis for seeking the most effective improvement solutions.

Stage 1 (SFI - Key failure factors identification): Firstly, the paired t-test was used to explore the failure gaps and degree of severity among the factors. Then, through the multiple regressions, the results for standardized regressor coefficients were viewed as the improvement opportunity for the proposed factors. In the next step, improvement rates were determined through considering the combination of severity degrees and regressor coefficients. The factors with higher improvement rate were identified as the e-learning key factors toward the overall satisfaction and learning effects.

Stage 2 (QFD - Recovery solution identification): After identifying the critical factors, it is essential to develop a set of effective e-learning quality improvement solutions. In order to seek the best solutions which can efficiently solve all relevant driving factors, it is extremely important to recognize the priority of factors in addition to their failure gaps and severity. Hence, the quality function deployment (QFD) method is utilized due to benefits in ensuring customer voices is systematically deployed throughout all planning and decision-making stages. As such, the achieved improvement solutions would effectively contribute to the elearning quality enhancement for the sake of learners and government organizations.

\section{Data analysis and Results}

The EFA approach was utilized to identify the critical factors among the above 38 factors. As a result, regarding e-learning provider dimension, 6 major factors were extracted from the original 31 factors, namely "hardware/software sufficiency, security and ease of use" (D1), "e-leaning course topics and instructions' professionalism" (D2), "assistance capability and e-learning support system management" (D3), "e-learning course curriculum and managers' support for e-learning use" (D4), "incentives mechanism" (D5), and "promotion and punishment mechanism" (D6). Concerning the e-learning learner dimension, 2 major factors were extracted from original 7 factors, namely "learners' professional background and operational skills" (D7) and "learning motivation" (D8).

The obtained 8 factors were then tested for internal consistency. All achieved Cronbach's $\alpha$ values ranged from 0.703 to 0.903 (satisfaction) and from 0.630 to 0.906 (degree of importance), construct reliability varied from 0.783 to 0.906 (satisfaction) and from 0.754 to 0.907 (degree of importance), all exceeded the recommended value of 0.7 , indicating a high internal consistency of the measurement items. Hence, reliability of all factors was ensured [7]. Moreover, since all factor loading values were greater than 0.4 , convergent validity of all measurement indicators was confirmed. The discriminant validity was and supported.

In the next step, the paired t-test was conducted to explore the failure gaps and severity degree. Then, the factors were determined for improvement opportunity through multiple regression. The results showed that factors D1, D2, D4, and D7 presented the highest improvement opportunities of $0.112,0.106,0.231$, and 0.152 , respectively, indicating their roles as key factors to e-learning satisfaction. 
In the final step, the QFD approach was employed to determine the most effective e-learning quality improvement solutions. 10 solutions were achieved through discussion with 5 experts, 3 managers, and 2 learners. 10 solutions proposed were A1 (establishment of elearning software use course), A2 (software operating navigation), A3 (plans for making learning passport), A4 (e-learning curriculum establishment), A5 (creation of e-learning support management team), A6 (creation of e-learning agency), A7 (instructors' professionalism enhancement), A8 (plans of learning outcomes appraisal), A9 (reward system for proactive participation), and A10 (course design in accordance with learning needs).

Then, based on the improvement rate of four key factors D1, D2, D4, and D7, 10 experts were asked to evaluate 10 proposed solutions using scores from 0 to 5 $(0=$ "completely unsolvable", $5=$ "completely resolvable"). Based on obtained scores, 10 solutions were ranked for recovery capability. As shown in Figure 1, the three top effective improvement solutions were $\mathrm{A} 8, \mathrm{~A} 6$, and $\mathrm{A} 9$.

\section{Conclusions}

The achieved results have successfully responded to the research purposes. Concerning the government organization case, this study has effectively found out 4 critical factors which are "hardware/software sufficiency and ease of use", "e-leaning course topics and instructions' professionalism", "e-learning course curriculum and managers' support for e-learning use", and "learners' professional background and operational skills". The findings strongly imply that in aiming to improve e-learning quality for the sake of organizational members and the organizations themselves, government organizations should focus on enhancing the creation of e-learning agency, learning outcomes ap- praisal, and reward system for proactive learning participation. This study hopes to beneficially provide future research with a useful innovative method and organization managers with helpful guidance for enhancing e-learning system for better organizational competitiveness.

\begin{tabular}{|c|c|c|c|c|c|c|c|c|c|c|c|c|c|}
\hline $\begin{array}{c}\text { Solution } \\
\text { Factor }\end{array}$ A1 & A2 & A3 & A4 & A5 & A6 & A7 & A8 & A9 & A10 & Severity & Improvement & Improve- \\
opportunity & ment tate \\
\hline D1 & 2.8 & 3.8 & 2.6 & 3 & 3.6 & 3.6 & 3.4 & 3.4 & 3.6 & 2.2 & 1.421 & 0.112 & 0.159 \\
\hline D2 & 3.8 & 4.2 & 3 & 3.4 & 3.4 & 3.6 & 4.6 & 4 & 3.4 & 4.6 & 1.483 & 0.106 & 0.157 \\
\hline D4 & 3.2 & 3.2 & 4.4 & 4.2 & 4.4 & 4.4 & 3.8 & 4.4 & 4.6 & 3.6 & 1.031 & 0.231 & 0.238 \\
\hline D7 & 4.6 & 4.2 & 3.8 & 4.2 & 3.6 & 3.8 & 3.6 & 4.4 & 3.6 & 3.6 & 0.980 & 0.152 & 0.149 \\
\hline Score & 2.49 & 2.65 & 2.50 & 2.64 & 2.69 & 2.75 & 2.70 & 2.87 & 2.74 & 2.47 & & & \\
\hline Rank & 9 & 6 & 8 & 7 & 5 & $\mathbf{2}$ & 4 & 1 & $\mathbf{3}$ & 10 & & & \\
\hline
\end{tabular}

Fig.1. The analysis of SFI-QFD

\section{Reference}

[1] P. C. Sun, J. T. Ray, G. Finger, and Y.Y. Chen (2008), "What drives a successful e-Learning? An empirical investigation of the critical factors influencing learner satisfaction," Computers \& Education, 50, pp. 1183-1202.

[2] A.M. Payne, J.E. Stephenson, W.B. Morris, H.G. Tempest, A. Mileham, D.K. Griffin (2009), "The use of an e-learning constructivist solution in workplace learning," International Journal of Industrial Ergonomics, 39, pp. 548553.

[3] E.Y. Huang, S.W Lin, T.K. Huang (2012), "What type of learning style leads to online participation in the mixed-modee-learning environment? A study of software usage instruction," Computers \& Education, 58, pp. 338-349.

[4] W. Bhuasiri, O. Xaymoungkhoun, H. Zo, J.J. Rho, A.P. Ciganek (2012), "Critical success factors for e-learning in developing countries: A comparative analysis between ICT experts and faculty," Computers \& Education, 58, pp. 843-855.

[5] S.S Liaw, H.M. Huang, G.D. Chen (2007), "Surveying instructor and learner attitudes toward e-learning," Computers \& Education, 49 (4), pp. 1066-1080.

[6] R. Iris, and A. Vikas (2011), "E-Learning technologies: A key to Dynamic Capabilities," Computers in Human Behavior, 27, pp. 18681874.

[7] J.C. Nunnally (1978), Psychometric theory, New York: McGraw-Hill. 